\title{
PENGARUH ORIENTASI KEWIRAUSAHAAN DAN PEMBELAJARAN ORGANISASIONAL TERHADAP INOVASI ORGANISASIONAL SERTA DAMPAKNYA TERHADAP KINERJA PERUSAHAAN
}

(Survei pada Perusahaan-Perusahaan Batik Trusmi Kecamatan Plered di Kabupaten Cirebon)

\author{
Raras Eka ${ }^{1}$, Syamsul Hadi Senen ${ }^{2}$, Suwatno ${ }^{3}$ \\ Mahasiswa Magister Manajemen Bisnis \\ Sekolah Pasca Sarjana Universitas Pendidikan Indonesia
}

\begin{abstract}
Abstrak
Tujuan penelitian ini adalah untuk menganalisis dan mengetahui pengaruh orientasi kewirausahaan, pembelajaran organisasional, inovasi organisasional terhadap kinerja perusahaan. Metode penelitian yang digunakan adalah deskriptif dan explanatory survey. Pengujian hipotesis menggunakan model persamaan struktural berbasis varian yang diproses dengan program Partial Least Square (PLS), dan ukuran sampel adalah 44 perusahaan. Kesimpulan Penelitian adalah Orientasi Kewirausahaan, Inovasi Organisasional, dan Kinerja Perusahaan sudah cukup baik namun Pembelajaran Organisasional masih belum baik; Orientasi Kewirausahaan berpengaruh positif terhadap Pembelajaran Organisasional; Orientasi Kewirausahaan berpengaruh positif terhadap Inovasi Organisasional; Pembelajaran Organisasional berpengaruh positif terhadap Inovasi Organisasional; Orientasi Kewirausahaan berpengaruh positif terhadap Kinerja Perusahaan; Pembelajaran Organisasional berpengaruh positif terhadap Kinerja Perusahaan; Inovasi Organisasional berpengaruh positif terhadap Kinerja Perusahaan; Orientasi Kewirausahaan berpengaruh terhadap Inovasi Organisasional secara langsung dan tidak langsung melalui Pembelajaran Organisasional; Orientasi Kewirausahaan berpengaruh terhadap Kinerja Perusahaan secara langsung dan tidak langsung melalui Inovasi Organisasional; dan Pembelajaran Organisasional berpengaruh secara langsung terhadap Kinerja Perusahaan.
\end{abstract}

Kata kunci: Orientasi Kewirausahaan, Pembelajaran Organisasional, Inovasi

Organisasional, dan Kinerja Perusahaan.

\section{PENDAHULUAN}

Industri kecil dan menengah (IKM) batik Cirebon berkembang pesat selama kurang lebih 10 tahun terakhir, hal ini terlihat dari meningkatnya jumlah unit usaha batik di Kabupaten Cirebon. Fenomena kinerja industri kecil dan menengah batik dapat ditunjukkan oleh Tabel 1.1 berikut ini:

Tabel 1.1

Nilai Produksi, Penjualan dan Laba Perusahaan Batik Trusmi Tabel 1.1

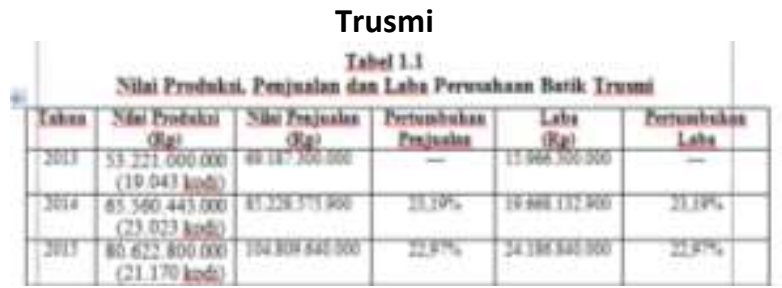

Sumber: Olah Data Peneliti

Hasil wawancara pendahuluan dengan pengusaha Batik Trusmi menunjukkan tetapnya tingkat pertumbuhan penjualan dan laba disebabkan oleh rata-rata besarnya laba adalah 30\% dari nilai produksi. Tingkat pertumbuhan penjualan dan laba yang tetap disebabkan pula oleh jumlah unit produksi yang relatif tetap. Jika dilihat dari pertumbuhan unit usaha, jumlah tenaga kerja, nilai produksi dan nilai ekspor produk Batik Trusmi dan batik nasional tampak pada Tabel 1.2 berikut ini:

Tabel 1.2

Pertumbuhan Jumlah Unit Usaha, Jumlah Tenaga Kerja, Nilai Produksi dan Nilai Ekspor Produk Batik Trusmi dan Batik Nasional

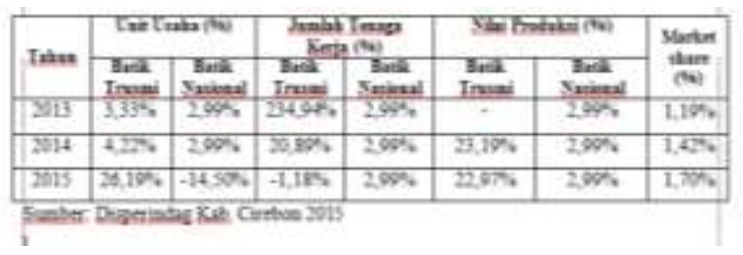

Menurunnya kinerja perusahaan-perusahaan Batik Trusmi karena berkurangnya tenaga kerja 
pembatik yang terampil di mana setiap unit usaha ratarata memiliki 10 (sepuluh) orang tenaga kerja. UKM batik yang memiliki 5 sampai 20 orang tenaga kerja menghasilkan 3 hingga 5 kodi per bulan sehingga dalam 1 tahun produksi yang dihasilkan setiap UKM sebanyak 60 kodi. Dari data jumlah unit usaha di Kecamatan Plered, rata-rata jumlah unit usaha setiap tahun adalah 400 unit sehingga kain batik yang dihasilkan sebanyak 24.000 kodi per tahun.

Menurut Ahmed \&

Shepherd (2010: 4), inovasi sangat penting dengan munculnya masyarakat berpengetahuan (knowledge society) dimana kreasi dan komersialisasi pengetahuan mendukung kesuksesan tingkat perusahaan dan nasional. Ide-ide baru, metode-metode baru, strukturstruktur baru dan produk-produk baru memiliki keampuhan untuk mendorong semangat organisasional dan pertumbuhan ekonomi. Ahmed \& Shepherd (2010: 474-533) menyatakan bahwa inovasi dapat tercapai melalui pelaksanaan pembelajaran organisasional, manajemen rantai suplai, dan manajemen pengetahuan. Pembelajaran organisasional (Organizational Learning) menjadi pemungkin inovasi organisasional (Organizational Innovation) karena melalui pembelajaran perbaikan yang kontinyu akan dilakukan oleh perusahaan jika perusahaan enggan untuk belajar melalui proses pembelajaran yang terus menerus maka perusahaan tersebut enggan berkembang dan akan padam suatu saat.

Tujuan umum penelitian adalah untuk menganalisis dan mengetahui pengaruh pembelajaran organisasional dan orientasi kewirausahaan terhadap kinerja perusahaan secara langsung dan tidak langsung melalui inovasi perusahaan-perusahaan Batik Trusmi Kecamatan Plered di Kabupaten Cirebon.

\section{KERANGKA PENELITIAN \& HIPOTESIS}

Kinerja organisasi menunjukkan bagaimana sebuah organisasi mencapai misi dan tujuannya, dan berakibat pada beberapa target yang tepat seperti proporsi market share, volume penjualan, motivasi karyawan, kepuasan pelanggan, dan kualitas (Sloota dan Verhoef, 2008 dalam Dehghan, A. \& Pool, J.K., 2015).

kinerja organisasi adalah: "Ukuran seberapa baik organisasi dikelola dan nilai yang mereka berikan kepada pelanggan dan stakeholder lainnya". Di sisi lain, keunggulan organisasi didefinisikan sebagai praktik yang luar biasa dalam mengelola organisasi dan memberikan nilai kepada pelanggan dan stakeholder lainnya (Moullin, 2007 dalam Antony, J.P. \& Bhattacharrya, S., 2010).

Definisi dari inovasi organisasional adalah: "Organizational innovation is a managerial innovation which includes the implementation of advanced management techniques such as the quality assurance program, International Standard for Organization (ISO 9000) or basic elements of TQM within the organization for the purpose of developing significant improvement in the production or delivery of goods or services" (Ismail, 2005: 641).

Templeton et al.'s (2002) adalah definisi yang disampaikan oleh Huber's (1991) yaitu: “Pembelajaran organisasional adalah suatu proses mengumpulkan pengetahuan, mendistribusikan, mengiterpretasikan berdasarkan konteks organisasional, dan menyimpan dalam memori suatu organisasi".

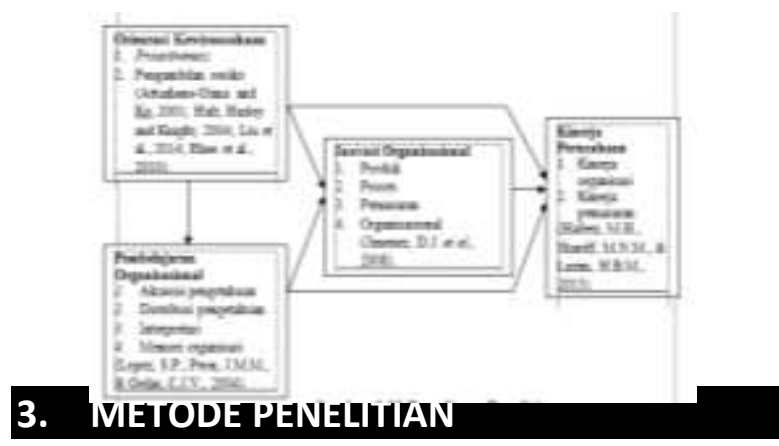

Penelitian ini dilakukan dengan tujuan untuk mengetahui pengaruh Pembelajaran Organisasional dan Orientasi Kewirausahaan terhadap inovasi serta dampaknya terhadap kinerja perusahaan sehingga jenis penelitian yang digunakan adalah verificative/explanation. Penelitian verifikatif digunakan karena jenis masalah penelitian ini adalah relational problems, kerangka konseptual adalah logical thinking, alternatif pemecahan masalah adalah relational hypothesis, dan pengujian hipotesis dengan 
menggunakan perhitungan-perhitungan statistik inferensial sehingga metode penelitian yang digunakan adalah Metode Survei Penjelasan (explanatory survey method) yaitu suatu metode survei untuk mengungkap kejelasan hubungan dan pengaruh antara variabel penelitian.

\section{HASIL DAN PEMBAHASAN}

Tabel 4.1 berikut menggambarkan nilai koefisien path atau inner model yang menunjukkan tingkat signifikansi dalam pengujian hipotesis.

Tabel 4.1

Nilai Koefisien Path: Mean, Standar Deviasi, T-Value, dan P-Value

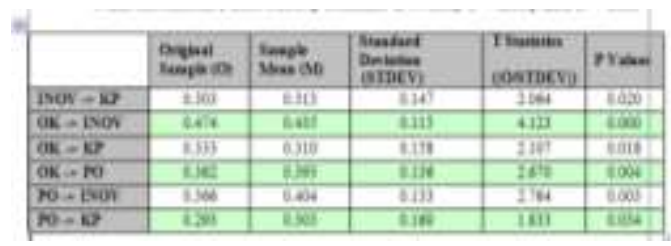

Tabel di atas digunakan untuk mengukur keterdukungan hipotesis. Ukuran keterdukungan hipotesis dapat digunakan perbandingan nilai T-tabel dan T-statistics. Jika nilai T-statistics lebih tinggi dibandingkan T-tabel berarti hipotesis terdukung. Untuk tingkat keyakinan 95\% (Alpha 5\%) maka nilai Ttabel untuk hipotesis one-tailed adalah $\geq 1,66$.

berikut ini merupakan diagram jalur lengkap model pengaruh pembelajaran organisasional dan orientasi kewirausahaan terhadap inovasi serta dampaknya terhadap kinerja perusahaan menggunakan metode Partial Least Square (PLS).

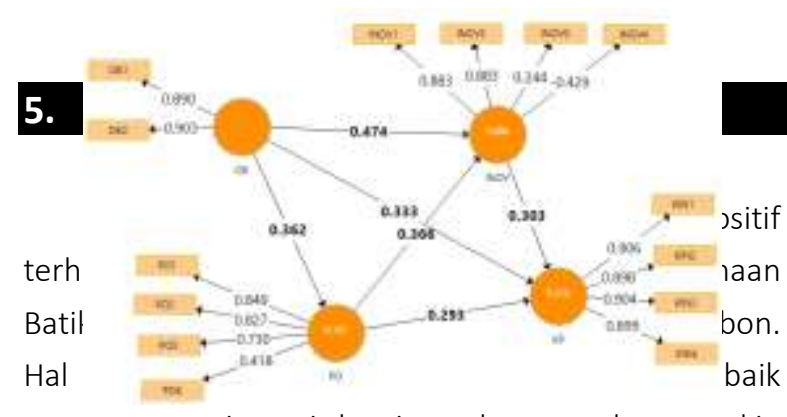
penerapan orientasi kewirausahaan maka semakin baik pula pembelajaran organisasional yang diterapkan perusahaan.

Orientasi kewirausahaan berpengaruh positif terhadap inovasi organisasional perusahaan Batik

\section{Gambar 4.1}

Diagram Jalur untuk Persamaan Struktural 1

Hasil yang ditunjukkan pada Gambar 4.2 menunjukkan bahwa loading factor dari inovasi pemasaran (inov4) adalah negatif sehingga inovasi pemasaran dikeluarkan dari model persamaan struktural. Inovasi pemasaran pada perusahaanperusahaan Batik Trusmi yang berskala kecil dan menengah berupa penggunaan media promosi dan perluasan daerah pemasaran secara online hanya dilakukan oleh beberapa perusahaan saja sehingga dapat disimpulkan bahwa inovasi pemasaran tidak dilakukan oleh sebagian besar perusahaanperusahaan Batik Trusmi di Kabupaten Cirebon.

\section{Uji Goodness of Fit (GOF)}

Uji kecocokan model (GOF) menunjukkan bahwa model dapat diterima, artinya model yang diperoleh dapat digunakan untuk menguji hipotesis penelitian yang telah ditetapkan. GOF dapat dihitung sebagai berikut:

$$
\begin{aligned}
& Q 2=1-(1-R 12))(1-R 22))(1-R 32)) \\
& Q 2=1-(1-0,131)(1-0,495)(1-0,560)=0,81
\end{aligned}
$$

Model memiliki nilai predictive value yang tinggi karena nilai Q2 mendekati 1.

Trusmi Kecamatan Plered di Kabupaten Cirebon. Hal tersebut menunjukkan bahwa semakin baik penerapan orientasi kewirausahaan maka semakin baik pula inovasi yang diterapkan perusahaan.

Pembelajaran organisasional berpengaruh positif terhadap inovasi organisasional perusahaan Batik Trusmi Kecamatan Plered di Kabupaten Cirebon. Hal tersebut menunjukkan bahwa semakin baik penerapan pembelajaran organisasional maka semakin baik pula inovasi yang diterapkan perusahaan.

Inovasi organisasional berpengaruh positif terhadap kinerja perusahaan-perusahaan Batik Trusmi 
Kecamatan Plered di Kabupaten Cirebon. Hal tersebut menunjukkan bahwa semakin baik penerapan inovasi maka semakin baik pula kinerja perusahaan yang dicapai perusahaan.

Orientasi kewirausahaan berpengaruh positif terhadap inovasi organisasional perusahaan secara langsung dan tidak langsung melalui pembelajaran organisasional pada perusahaan-perusahaan Batik Trusmi di Kabupaten Cirebon. OL merupakan variabel intervening EO dengan Inovasi.

Orientasi kewirausahaan berpengaruh positif terhadap kinerja perusahaan secara langsung dan tidak langsung melalui inovasi organisasional pada perusahaan-perusahaan Batik Trusmi Kecamatan Plered di Kabupaten Cirebon. Inovasi merupakan variabel intervening antara OL dan EO dengan Kinerja Perusahaan.

Pembelajaran organisasional berpengaruh positif terhadap kinerja perusahaan secara langsung. Inovasi organisasional bukan variabel intervening antara Pembelajaran Organisasional dan Kinerja Perusahaan.

\section{REKOMENDASI}

1. Untuk meningkatkan penerapan pembelajaran organisasional, perusahaan Batik Trusmi disarankan untuk:

a) Meningkatkan kemampuan mendapatkan informasi dari luar perusahaan tentang pemasok, pelanggan, dan pesaing.

b) Meningkatkan kemampuan berbagai pengetahuan diantara karyawan dan pengusaha.

c) Meningkatkan kemampuan menginterpretasikan pengetahuan tentang produk, bahan baku, pelanggan, dan pesaing.

Hal tersebut dilakukan perusahaan melalui sosialisasi dari pemiliki perusahaan/pengusaha.

2. Untuk meningkatkan inovasi organisasional, perusahaan-perusahaan Batik Trusmi harus memiliki orientasi kewirausahaan yang sudah baik yang diperoleh dengan meningkatkan perilaku proaktif sehingga dapat mengisi peluang-peluang bisnis; juga dengan cara meningkatkan keberanian mengambil resiko dengan cara mengalokasikan sumber daya peralatan, bahan baku, dan sumber daya manusia yang dimiliki untuk pengembangan bisnis, memperbaiki produk dan teknik produksi.

3. Untuk meningkatkan kinerja perusahaan, perusahaan-perusahaan Batik Trusmi harus memiliki inovasi organisasional yang sudah baik. $\mathrm{Hal}$ tersebut diperoleh dengan meningkatkan kebaruan produk, kebaruan penggunaan bahan baku, kebaruan teknik produksi, keaslian membuat desain, corak kain batik, keaslian desain baju batik, keunikan corak kain batik, keunikan teknik produksi, keunikan warna kain batik, keunikan teknik pewarnaan kain batik, keunikan teknik produksi baju batik.

4. Untuk meningkatkan kinerja perusahaan, perusahaan-perusahaan Batik Trusmi disarankan untuk meningkatkan omzet penjualan melalui perluasan metode penjualan; meningkatkan tingkat produksi dengan cara pemberdayaan perajin batik.

\section{DAFTAR PUSTAKA}

Ahmed, P.K. \& Shepherd, C.D. (2010). Innovation Management. England: Pearson Education Limited.

Biazzo, S. \& Garengo, P. (2012). Performance Measurement with the Balanced Scorecard: Practical Approach to Implementation within SMEs. New York: Springer Heidelberg Dordrecht London New York.

Affendy A. H. dkk. (2015). Entrepreneurial Orientation Effects on Market Orientation ans SMEs Business Performance-A SEM Approach. Rev. Integr. Bus. Econ. Res Vol. 4 (3) hlm. 259-271. Society of Interdisciplinary Business Research.

Beyene, K. T., Shi, C. S., \& Wu, W. W. (2016). Linking Culture, Organizational Learning Orientation and Product Innovation Performance: The Case of Ethiopian Manufacturing Firms. South African Journal of Industrial Engineering Vol. 27 (1) hlm. 88-101.

Bolton, D. L. \& Lane, M. D. (2012). Individual Entrepreneurial Orientation: Development of a Measurement Instrument. Education $p$ Training 
Vol. 54, No. 2/3 hlm. 219-233. Emerald Group Publishing Limited.

Dehghan, A. \& Pool, J. K. (2015). The Effects of Customer and Entrepreneural Orientation on Innovativeness and Performance. International Journal of Arts \& Sciences CD-ROM. ISSN: 19446934 :: 08(04): hlm. 357-364.

Dotun, F. O. (2015). The Key Determinants of Innovation in Small and Medium Scale Enterprises in Southwestern Nigeria. European Scientific Journal Vol. 11, No. 13 hlm. 465-479.

Pingit Aria. 2016. Berlaku Tahun Ini, Apa Itu MEA?, diakses 7 Oktober 2016 pada website https://m.tempo.co/read/news/29016/01/07/ 090734103/berlaku-tahun-ini-apa-itu-mea.

2016. BKPI Ikuti Kunjungan Bakohumas ke Sentra Batik Trusmi Cirebon, diakses 7 Oktober 2016 pada website http://bkhn.lipi.go.id/bkpiikuti-kunjungan-bakohumas-ke-sentra-batiktrusmi-cirebon/. 